\title{
Deletion of the Presynaptic Scaffold CAST Reduces Active Zone Size in Rod Photoreceptors and Impairs Visual Processing
}

\author{
Susanne tom Dieck, ${ }^{1 \star}$ Dana Specht, ${ }^{1,2 \star}$ Nicola Strenzke, ${ }^{3,4,5}$ Yamato Hida, ${ }^{7}$ Vidhyasankar Krishnamoorthy, ${ }^{6}$ \\ Karl-Friedrich Schmidt, ${ }^{8}$ Eiji Inoue, ${ }^{9}$ Hiroyoshi Ishizaki, ${ }^{9}$ Miki Tanaka-Okamoto, ${ }^{10}$ Jun Miyoshi, ${ }^{10}$ Akari Hagiwara, ${ }^{7}$ \\ Johann H. Brandstätter, ${ }^{2}$ Siegrid Löwel, ${ }^{8}$ Tim Gollisch, ${ }^{6}$ Toshihisa Ohtsuka, ${ }^{7}$ and Tobias Moser ${ }^{4,5}$ \\ ${ }^{1}$ Department of Synaptic Plasticity and Department of Neuroanatomy, Max Planck Institute for Brain Research, D-60528 Frankfurt/Main, Germany, ${ }^{2} \mathrm{Animal}$ \\ Physiology, Department of Biology, Friedrich Alexander University Erlangen-Nürnberg, D-91058 Erlangen, Germany, ${ }^{3}$ Auditory Systems Physiology Group, \\ ${ }^{4}$ InnerEarLab, Departments of ${ }^{5}$ Otolaryngology and ${ }^{6}$ Ophthalmology, Sensory Collaborative Research Center 889, University of Göttingen School of Medicine, D- \\ 37099 Göttingen, Germany, ${ }^{7}$ Department of Biochemistry, Graduate School of Medicine/Faculty of Medicine, University of Yamanashi, Chuo, Yamanashi 409-3898 \\ Japan, ${ }^{8}$ Department of Systems Neuroscience, Bernstein Focus Neurotechnology, Johann Friedrich Blumenbach Institute for Zoology and Anthropology and \\ Sensory Collaborative Research Center 889, University of Göttingen, D-37075 Göttingen, Germany ${ }^{9}$ Knowledge Action Network Research Institute, Chuo-ku, Kobe \\ 650-0047, Japan, and ${ }^{10}$ Department of Molecular Biology, Osaka Medical Center for Cancer and Cardiovascular Diseases, Osaka 537-8511, Japan
}

How size and shape of presynaptic active zones are regulated at the molecular level has remained elusive. Here we provide insight from studying rod photoreceptor ribbon-type active zones after disruption of CAST/ERC2, one of the cytomatrix of the active zone (CAZ) proteins. Rod photoreceptors were present in normal numbers, and the a-wave of the electroretinogram (ERG) - reflecting their physiological population response-was unchanged in CAST knock-out $\left(\mathrm{CAST}^{-/}\right)$mice. Using immunofluorescence and electron microscopy, we found that the size of the rod presynaptic active zones, their $\mathrm{Ca}^{2+}$ channel complement, and the extension of the outer plexiform layer were diminished. Moreover, we observed sprouting of horizontal and bipolar cells toward the outer nuclear layer indicating impaired rod transmitter release. However, rod synapses of $\mathrm{CAST}^{-/-}$mice, unlike in mouse mutants for the CAZ protein Bassoon, displayed anchored ribbons, normal vesicle densities, clustered $\mathrm{Ca}^{2+}$ channels, and essentially normal molecular organization. The reduction of the rod active zone size went along with diminished amplitudes of the b-wave in scotopic ERGs. Assuming, based on the otherwise intact synaptic structure, an unaltered function of the remaining release apparatus, we take our finding to suggest a scaling of release rate with the size of the active zone. Multielectrode-array recordings of retinal ganglion cells showed decreased contrast sensitivity. This was also observed by optometry, which, moreover, revealed reduced visual acuity. We conclude that CAST supports large active zone size and high rates of transmission at rod ribbon synapses, which are required for normal vision.

\section{Introduction}

The structure of presynaptic active zones is adapted to accommodate the specific functional requirements of a given synapse (Zhai and Bellen, 2004; Moser et al., 2006; Matthews and Fuchs, 2010;

Received Feb. 14, 2012; revised June 5, 2012; accepted July 4, 2012.

Author contributions: S.t.D., J.H.B., S.L., T.G., T.O., and T.M. designed research;S.t.D., D.S., N.S., Y.H., V.K., K.-F.S., E.I., H.I., M.T.-O., J.M., A.H., T.G., and T.O. performed research; S.t.D., D.S., N.S., Y.H., V.K., K.-F.S., E.I., H.I, M.T.-O., J.M., A.H., J.H.B., S.L., T.G., T.O., and T.M. analyzed data; S.t.D., S.L., T.G., T.O., and T.M. wrote the paper.

This work was supported by grants from the Ministry of Education, Culture, Sports, Science, and Technology of Japan [Grant-in-Aid for Scientific Research (B) 22300120 and Scientific Research on Priority Areas (Molecular Brain Science)] and the Uehara Foundation (T.O.), the German Research Foundation (T.M., N.S., T.G. and S.L. via the Collaborative Research (enter 889 and to J.H.B.) Grant BR 1643/4-1, the German Initiative of Excellence and the International Human Frontier Science Program Organization (T.G.), and German Federal Ministry of Education and Research Bernstein Center for Computational Neuroscience Grant 01GQ1005A (T.M.) and Bernstein Focus for Neurotechnology Grant 01GQ0810 (S.L. and T.M.). We thank Dr. Carolin Wichmann for comments on this manuscript and Christian Rüdiger, Stefan Thom, Margitta Köppler, and Nina Dankenbrink-Werder for their contributions.

*S.t.D. and D.S. contributed equally to this work.

The authors declare no competing financial interests.

Correspondence should be addressed to either of the following: Dr. Toshihisa Ohtsuka, Department of Biochemistry, Graduate School of Medicine/Faculty of Medicine, University of Yamanashi, 1110 Shimokato, Chuo, Yamanashi 409-3898 Japan; or Dr. Tobias Moser, InnerEarLab, Department of Otolaryngology and Sensory Collaborative Research Center 889, University of Göttingen School of Medicine, 37099 Göttingen, Germany. E-mail: tmoser@gwdg.de.

DOI:10.1523/JNEUROSC1.0752-12.2012

Copyright $\odot 2012$ the authors $\quad 0270-6474 / 12 / 3212192-12 \$ 15.00 / 0$
Gundelfinger and Fejtova, 2011). The mechanisms regulating active zone size are not well understood but likely to involve Liprins/Syd proteins (Stigloher et al., 2011), cytomatrix of the active zone (CAZ) proteins, such as CAST/ELKS (Kittel et al., 2006), Bassoon and Piccolo (Zhai et al., 2000, 2001), and, at ribbon synapses, also RIBEYE (Sheets et al., 2011). Some synapses, such as the neuromuscular junction or ribbon synapses of photoreceptors, and hair cells use large active zones to accommodate high rates of synaptic transmission. There, tens of $\mathrm{Ca}^{2+}$ channels and docked synaptic vesicles are organized in well-ordered arrays, thought to adhere to a specific topographic principle that favors tight control of vesicle fusion by nearby $\mathrm{Ca}^{2+}$ channels (Harlow et al., 2001; Wachman et al., 2004; Brandt et al., 2005; Frank et al., 2010; Jarsky et al., 2010). The CAZ proteins Bassoon, RIM, Piccolo, CAST/ERC2 (termed CAST in the following), and ELKS/ ERC1 are thought to mediate these organizational principles during and after synapse formation (Fejtova and Gundelfinger, 2006; Hida and Ohtsuka, 2010). Indeed, ablation of long RIM isoforms reduced both the number of presynaptic $\mathrm{Ca}^{2+}$ channels and the number of docked vesicles, resulting in a reduction of the readily releasable pool (RRP) of vesicles at the calyx of Held, a large auditory synapse with many small active zones mediating 
high throughput of vesicles (Han et al., 2011). Similarly, the disruption of Bassoon led to a reduced RRP at hair cell synapses (Khimich et al., 2005), again as a result of fewer synaptic $\mathrm{Ca}^{2+}$ channels and tethered vesicles (Frank et al., 2010). Bassoon disruption also caused a loss of anchored ribbons in both photoreceptors (Dick et al., 2003; tom Dieck et al., 2005) and hair cells (Khimich et al., 2005) and impaired vesicle replenishment at high-throughput synapses (Frank et al., 2010; Hallermann et al., 2010). However, it had no measurable effect on active excitatory synapses of hippocampal neurons (Altrock et al., 2003) even in the absence of Piccolo (Mukherjee et al., 2010). Moreover, these neurons, which signal at lower rates than, for example, sensory cells and neurons, were unaffected also by ablation of CAST (Kaeser et al., 2009). This is in contrast to the strong synaptic phenotype found at Drosophila neuromuscular junction during disruption of the CAST paralog Bruchpilot (Kittel et al., 2006). In the absence of Bruchpilot, the electron-dense T-bars were no longer visible and $\mathrm{Ca}^{2+}$ channel clusters were dissolved.

Here we disrupted CAST function and studied the large ribbon synapses of rod photoreceptors. We demonstrate smaller but otherwise seemingly intact active zones. Impaired electroretinogram (ERG), dendritic sprouting of bipolar and horizontal cells into the outer nuclear layer (ONL), and decreased contrast sensitivity and visual acuity indicated an impaired rod synaptic transmission probably resulting from the decreased active zone size. We conclude that CAST is required for establishing/stabilizing large-sized rod photoreceptor ribbon-type active zones and for normal vision.

\section{Materials and Methods}

All experiments complied with national animal care guidelines and the guidelines issued by the Max Planck Society, the Knowledge Action Network Research Institute and the University of Göttingen and were approved by local authorities. Animals of either sex were used because no sex differences were observed.

Generation of the $\mathrm{CAST}^{-1-}$ mice. CAST knock-out $\left(\mathrm{CAST}^{-/-}\right)$mice were generated by homologous recombination in embryonic stem (ES) cells. In the targeting vector (Fig. 1A), sequence coding for amino acids $1-130$ of CAST in the first coding exon were replaced by a neomycin resistance cassette. Recombinant ES cell clones were analyzed by Southern blotting using a $5^{\prime}$ probe. Positive clones were injected into mouse blastocysts to obtain highly chimeric mice that transmitted the mutation through the germ line. Germ-line transmission of the mutation was confirmed by Southern blotting (Fig. $1 B$ ) and PCR genotyping (Fig. $1 C$ ). Genotypes were determined by PCR using the following primers: $C A S T^{+/+}$forward, $5^{\prime}$-ATGTACGGGAGCGCAAGAACAATC- $3^{\prime}$; CAST $^{+/+}$reverse, $5^{\prime}$-CGTATAGGAAAGGACATCCGTGTG-3' $3^{\prime}$ CAST ${ }^{-1-}$ forward, $5^{\prime}$-GACATAGCGTT GGCTACCCGT-3'; CAST ${ }^{-1-}$ reverse, 5'-GGGCTTGAAGATCCAACATCG-3'. The CAST ${ }^{+/+}$and $C A S T^{-/}$alleles produced 354 and $290 \mathrm{bp}$ products, respectively, in PCR genotyping (Fig. 1C).

Retinal tissue preparation for light microscopic immunocytochemistry. Preparation of retinal tissue and antibody incubation for light microscopy was performed as described previously (Dick et al., 2001) by immersion fixation in $4 \%$ paraformaldehyde, cryoprotection with increasing sucrose concentrations, and embedding in TissueTek (Sacura Finetek Europe) for cryosectioning (Dick et al., 2001). The retinal sections were blocked for $1 \mathrm{~h}$ in blocking solution (10\% normal goat serum, $0.5 \%$ Triton X-100 in phosphate buffer) and incubated in the primary antibodies in $3 \%$ normal goat serum, $0.5 \%$ Triton X-100 in phosphate buffer overnight at room temperature. After being washed three times in PBS, sections were incubated with secondary antibodies for $1 \mathrm{~h}$ at room temperature in the dark. Images were taken with a Carl Zeiss confocal laser-scanning microscope (LSM5 Pascal; Carl Zeiss) and a Carl Zeiss Axio Imager.Z1 equipped with an ApoTome (Carl Zeiss). Images were adjusted for contrast and brightness using Adobe Photoshop CS, and figures were arranged using Adobe Photoshop and Adobe Illustrator.
Width measurement of the outer plexiform layer. The entire, dorsoventrally oriented retinae were immersion fixed with $4 \%$ paraformaldehyde, cryoprotected with increasing sucrose concentrations, and embedded in TissueTek in the eye cup. Twenty micrometer vertical cryosections were initially stained with an antibody against CtBP2. To label the cell nuclei, additionally, a DAPI staining was performed by 5 min incubation in DAPI solution $(0.1 \mu \mathrm{g} / 1 \mathrm{ml}$ PBS), followed by several washing steps. Overlapping images were taken with an ApoTome (Carl Zeiss), processed, magnified, and pasted together in Adobe Photoshop CS. The width was repeatedly measured along the outer plexiform layer (OPL), both from inner nuclear layer (INL) nuclei border to ONL nuclei border (= total OPL width) and for the area occupied by CtBP2-stained ribbons (= synaptic) at intervals corresponding to $5 \mu \mathrm{m}$ and averaged. For both wild-type $\left(\mathrm{CAST}^{+/+}\right)$and $C A S T^{-/-}$, three animals were analyzed, a minimum of 120 width measurements were performed per animal, and the statistical significance of the differences between the genotypes was tested with a two-tailed $t$ test. In total, $>550$ data points were taken per genotype. For these measurements, only sections from the area around the optic nerve were used to exclude differences attributable to physiological differences in the various areas of the retina.

Photoreceptor nucleus count in the ONL. To assess whether there was a reduction of photoreceptor numbers in $C A S T^{-1-}$ mice, we analyzed three areas of each $100 \times 250$ pixel corresponding to $20 \times 50 \mu \mathrm{m}$ of the same micrographs used for measurements of OPL width. Areas were chosen spanning the whole width of the ONL in an area adjacent to the emergence of the optic nerve in which the ONL width became constant. The numbers of DAPI-stained nuclei in the $1000 \mu \mathrm{m}^{2}$ areas were counted and averaged per animal, and the genotypes were compared. Statistical analysis was performed in GraphPad Prism using a one-way ANOVA and a two-tailed $t$ test.

Ribbon length measurement and semiquantitative analysis of $\mathrm{Ca}_{V} 1.4 \mathrm{immu-}$ noreactivity. Pairs of $\mathrm{CAST}^{+/+}$and $C A S T^{-/-}$retinae were processed for immunohistochemistry as described above and frozen as sample pair on top of each other in TissueTek. Cryosectioning and all subsequent antibody labeling steps for $\mathrm{CtBP} 2$ ribbon and $\mathrm{Ca}_{\mathrm{V}} 1.4$ (Cacnalf) staining were performed on paired samples to guarantee comparable conditions for staining of $\mathrm{CAST}^{+/+}$and $\mathrm{CAST}^{-/-}$tissue. Samples were imaged and micrographs processed under similar conditions for each genotype pair. Collapsed image stacks were converted to .tiff files in the LSM5 Pascal3.2SP2 software, and the length of the ribbons in one field of view was measured regardless of their orientation using the measurement tool of the software by overlaying a path along the midline of the ribbon. Corresponding values were transferred to GraphPad Prism and analyzed ( $n=3$ animals per genotype; $>120$ ribbons per animal). Statistical analysis was performed using a Kruskal-Wallis test and the Dunn's multiple comparison test for one-to-one comparison.

$\mathrm{Ca}_{\mathrm{V}} 1.4$ immunofluorescence intensity was measured as the integral of the pixel values under the two-dimensional Gaussian fitted to the individual ribbon-associated $\mathrm{Ca}_{\mathrm{V}} 1.4$ immunofluorescence after subtraction of the background (estimated by fitting a linear function to the region outside of the 2D Gaussian and subsequently subtracting this function from the entire image) as done previously in hair cells (Frank et al., 2010).

Electron microscopy. For conventional electron microscopy, retinae were immersion fixed in the eye cup with $2.5 \%$ glutaraldehyde and $4 \%$ $\mathrm{p}$-formaldehyde for $2 \mathrm{~h}$. The contrasting was performed in potassium ferrocyanide and $2 \%$ osmium tetroxide in cacodylate buffer. Specimens were dehydrated using an ethanol series and propylene oxide with $0.5 \%$ (w/v) uranyl acetate added at the $70 \%$ ethanol step. Final steps were performed as described previously (Regus-Leidig et al., 2010).

For electron microscopic analysis, ultrathin sections were examined and photographed with a Carl Zeiss EM10 electron microscope and a Gatan BioScan digital camera in combination with the DIGITAL Micrograph 3.1 software (Gatan). For vesicle densities, the number of vesicles directly attached to the ribbon were counted at each profile and divided by the ribbon profile length visible in the micrograph [two animals per genotype, $n=14\left(\mathrm{CAST}^{+/+}\right)$and $15\left(\mathrm{CAST}^{-/-}\right)$profiles in total].

Antibodies. Antibodies were used for immunocytochemistry (ICC) and Western blot (WB) in the following dilutions: rabbit anti-CAST/ Erc2 (1:1000 for WB 1:500 for ICC; Ohtsuka et al., 2002; tom Dieck et al., 2005), rabbit anti-ELKS (1:500 for WB; Deguchi-Tawarada et al., 2006), 
mouse anti-Tubulin (1:1000 for WB; Oncogene), rabbit anti-Cacnalf(Pep3) (1:5000 for ICC; Specht et al., 2009); mouse anti-Cacnals (mab1A; 1:5000 for ICC), rabbit anti-PKC $\alpha$ (1: 1000 for ICC; Sigma), rabbit anti-mGluR6 (1:100 for ICC; Neuromics), rabbit anti-Veli3 (1:1000 for ICC; Zymed), mouse anti-CtBP2/RIBEYE (1: 10,000 for ICC; 1:1000 for WB; BD Biosciences), guinea pig anti-Piccolo (1:8000 for ICC; kindly provided by E. Gundelfinger, Magdeburg, Germany), mouse anti-Bassoon (mab7f; 1:2500 for ICC; Stressgen), rabbit anti-Calbindin (1:1000 for ICC; Swant), anti-b-dystroglycan (1:500 for ICC; Novocastra), and rabbit anti-RIM2-Znfinger (1:500; Synaptic Systems).

Secondary antibodies were raised in goat and coupled to Alexa Fluor 488 or Alexa Fluor 594 (1:500; Invitrogen) for ICC or to horseradish peroxidase (goat anti-rabbit HRP, 1:40,000; New England Biolabs) for WB.

$W B$. For WBs, retinae were homogenized in a homogenization buffer $(0.32 \mathrm{M}$ sucrose, $1 \mathrm{~mm}$ $\mathrm{NaHCO}_{3}, 1 \mathrm{~mm} \mathrm{MgCl}$, and $0.5 \mathrm{~mm} \mathrm{CaCl}$ ), and total protein was dissolved in an SDS sample, separated on $7.5-10 \%$ SDS-PAGE, and transferred to nitrocellulose membranes by tank blotting. For immunodetection, membranes were blocked and primary antibodies were applied for $1 \mathrm{~h}$ at room temperature. The HRP-coupled secondary antibodies were visualized by chemiluminescent detection. Band intensity was assessed using NIH ImageJ software. The intensity of each band of the processed fragment was normalized to $\mathrm{CAST}^{+/+}$ mice.

$E R G$ recordings. Mice were dark adapted overnight and anesthetized by intraperitoneal injection of ketamine $(125 \mu \mathrm{g} / \mathrm{g})$ and xylazine $(2.5 \mu \mathrm{g} / \mathrm{g})$, and one pupil was dilated with $1 \%$ atropine sulfate. All preparations were done under dim red light. A ring-like $\mathrm{AgCl}$ wire electrode, moistened by methylcellulose and $\mathrm{NaCl}$ solutions, was placed on the cornea, and a needle reference electrode was inserted subcutaneously above the nose and a ground electrode near the tail. A custom-designed Ganzfield illuminated by 25 white LEDs was used to produce light flashes of incremental luminances $\left(0.0002\right.$ to $14 \mathrm{~cd} / \mathrm{m}^{2}$; measured by Mavolux, IPL 10530). Scotopic responses were recorded for a stimulus duration of $0.1 \mathrm{~ms}$ with an interstimulus interval of $5 \mathrm{~s}$. Recorded potentials were amplified, filtered (bandpass: 400-4000 $\mathrm{Hz}$ ), and sampled at a rate of $24 \mathrm{kHz}$. Ten responses were averaged per light intensity. For analysis, amplitudes of the a-wave were measured relative to the baseline, whereas the b-wave amplitudes were estimated relative to the trough of the a-wave. Oscillatory potentials were sorted by $30-400 \mathrm{~Hz}$ bandpass filtering, and the peak-to-peak amplitudes were assessed. Latencies of the a- and b-waves were determined as the temporal difference between light onset and time of peak. All data were analyzed using MATLAB software. Statistical significance was tested by an unpaired, two-tailed $t$ test.

Ganglion cell recordings. Spike trains of retinal ganglion cells were recorded extracellularly
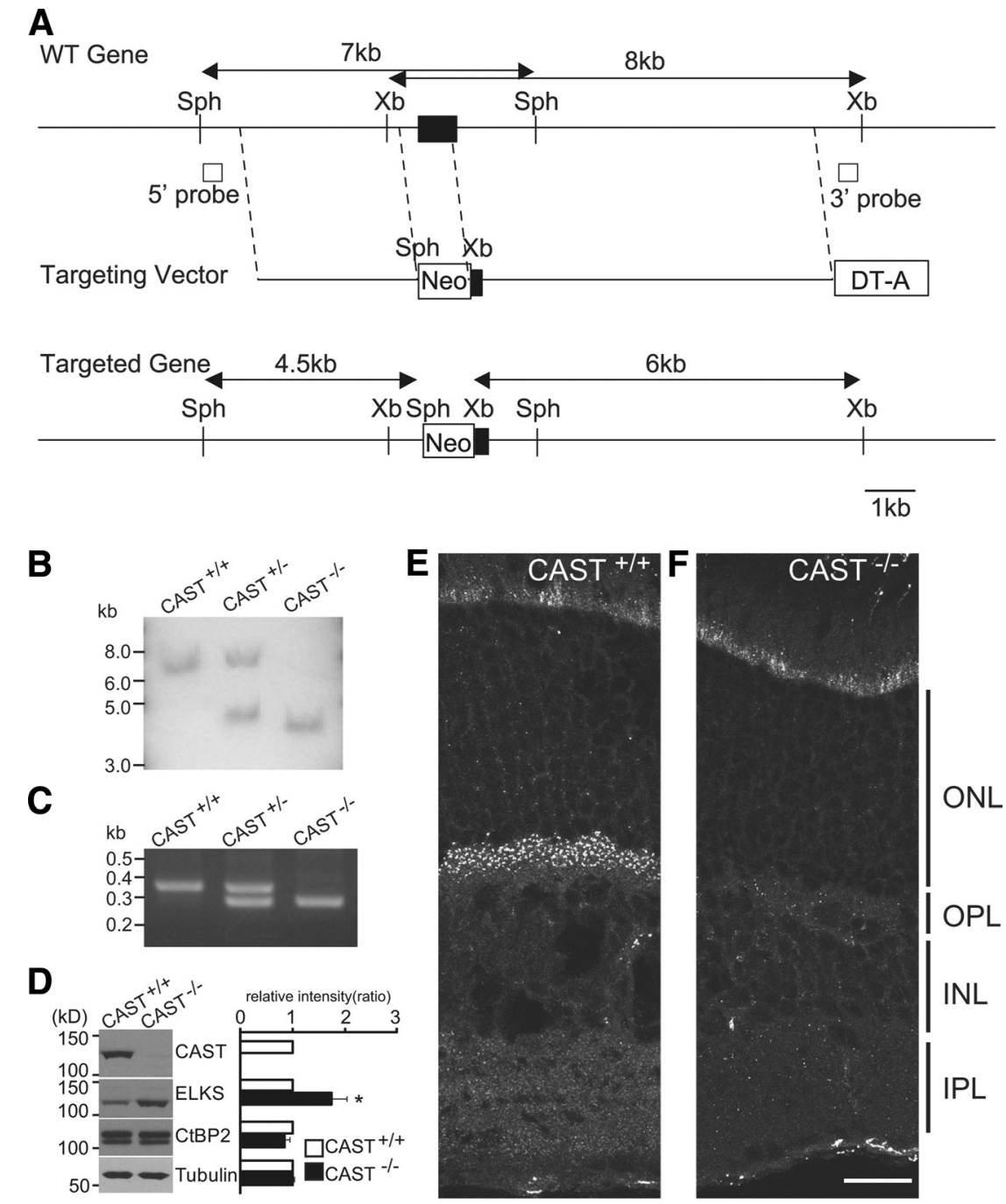

G

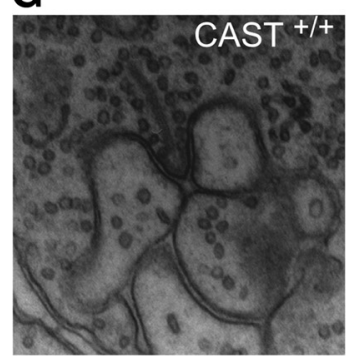

H

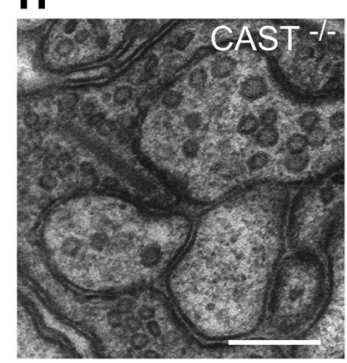

I

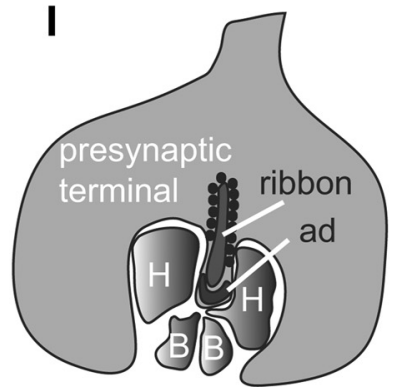

Figure 1. Synaptic ribbons are anchored in photoreceptors of CAST ${ }^{-/-}$mice. $A$, Maps of the WT CAST gene, targeting vector, and the resulting mutant gene. Position of first exon (black box), restriction enzyme sites, and position of $5^{\prime}$ and $3^{\prime}$ probes (white box) are indicated. Neo, Neomycin; DT-A, diphtheria toxin-A; Sph, Sphl;Xb, Xbal. B, Southern blot analysis of targeted mice. C, PCR analysis of targeted mice. $\boldsymbol{D}$, WB of protein homogenate (20 $\mu \mathrm{g} /$ lane except for Tubulin, $2 \mu \mathrm{g} / \mathrm{lane}$ ) isolated from retina of $\mathrm{CAST}^{+/+}$and $\mathrm{CAST}^{-/-}$and stained with indicated antibodies showed absence of CAST and significant increase of ELKS immunoreactive band in the retina of $\mathrm{CAST}^{-/-}$mice. No significant changes were found in the expression of the ribbon synapse marker RIBEYE (stained by CtBP2 antibody) and Tubulin examined here. ELKS expression level was upregulated $1.74 \pm 0.29$-fold in CAST $^{-1-}$ mice. ${ }^{*} p<0.05, n=3$, unpaired Student's $t$ test; error bars represent the SD. Filled and open bars represent the data of $\mathrm{CAST}^{-/-}$and $C A S T^{+/+}$, respectively. The value was normalized to that of $C A S T^{+/+}$mice for each protein. $\boldsymbol{E}, \boldsymbol{F}$, Micrograph of vertical sections of $\mathrm{CAST}^{+/+}(\boldsymbol{E})$ and CAST $^{-/-}(\boldsymbol{F})$ retina with anti-CAST antibody. The prominent staining of CAST seen in the $\mathrm{CAST}^{+/+}$ribbon synapses in the OPL is absent in sections of $\mathrm{CAST}^{-/-}$mice. $\mathbf{G}-\mathbf{I}$, Electron micrographs of cross-sections of rod ribbon synapses from $\mathrm{CAST}^{+/+}(\boldsymbol{G})$ and $\mathrm{CAST}^{-/-}(\boldsymbol{H})$ retina show no obvious difference in ribbon synapse architecture. The scheme $(I)$ shows the general configuration of this complex synapse: rod spherules have ribbons anchored to the active zone. The electron-dense arciform density is clearly visible, and several postsynaptic elements from horizontal $(H)$ and bipolar $(B)$ cells invaginate into the presynaptic terminal. ad, Arciform density. Scale bars: $\boldsymbol{E}, \boldsymbol{F}, 20 \mu \mathrm{m} ; \boldsymbol{G}, \boldsymbol{H}, 200 \mathrm{~nm}$. 


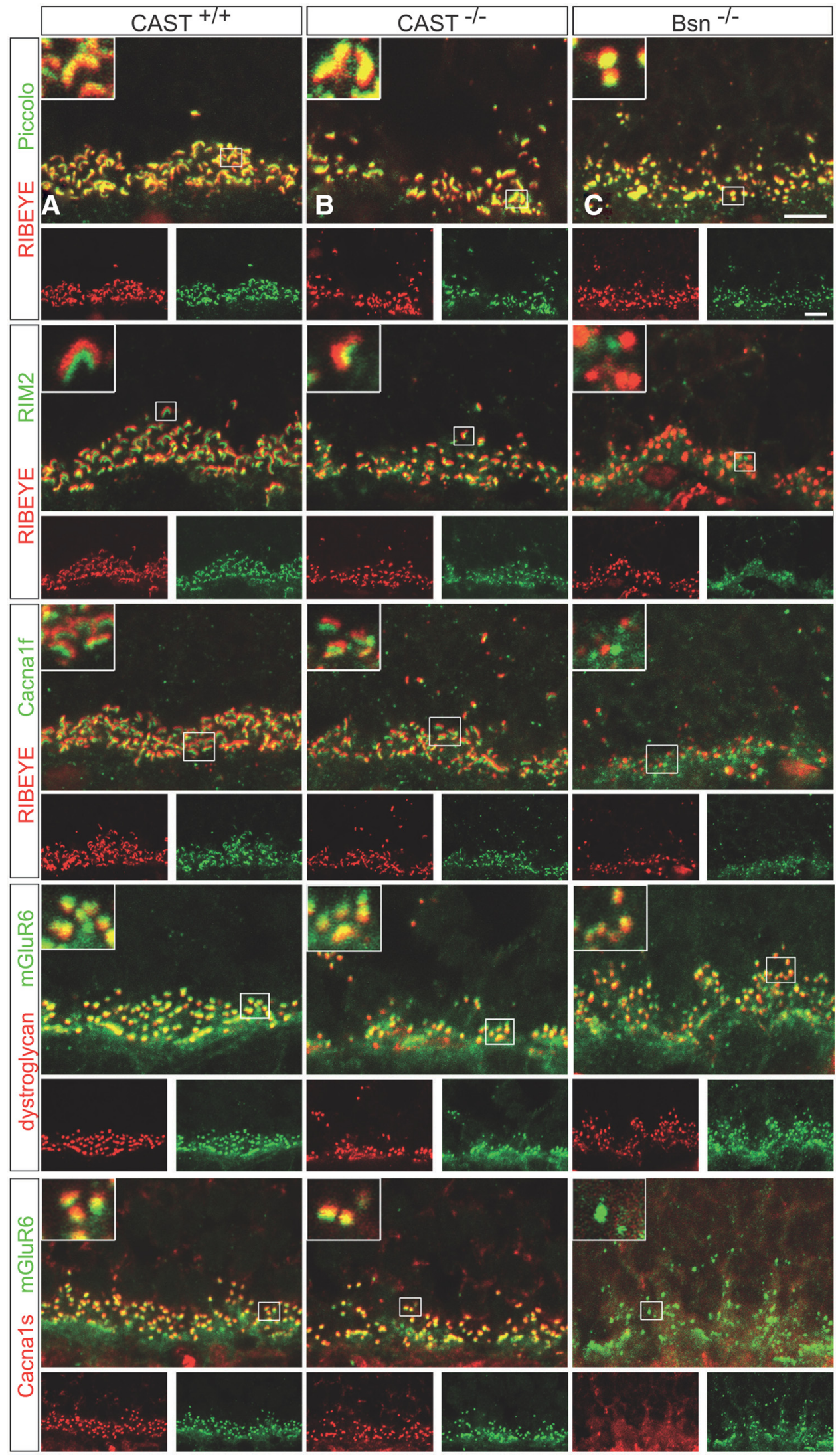

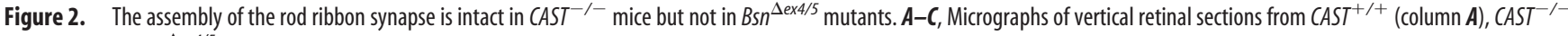
(column $\boldsymbol{B}$ ), and $B s n^{\Delta e x 4 / 5}$ (column $C$ ) mice were stained with combinations of antibody markers for distinct compartments of the ribbon synapse. Ribbon markers Piccolo and RIBEYE colocalized in all genotypes. Whereas ribbons had an elongated appearance in $\mathrm{CAST}^{+/+}$and $C A S T^{-/-}$mice, RIBEYE and Piccolo staining had a punctate appearance in Bassoon mutants, in which ribbon material is floating freely in the cytoplasm. In CAST ${ }^{+/+}$and $\mathrm{CAST}^{-/-}$mice, the arciform density protein RIM2 lined the RIBEYE staining at the concave inside, as did the staining of active zone plasma membrane $\mathrm{Ca}^{2+}$ channel $\mathrm{Ca}_{\mathbf{y}} 1.4$ (Cacna1f). In retinas of $B s n^{\Delta e x 4 / 5}$ mutants, both RIM2 and Cacna1f showed hotspots that were separated from RIBEYE puncta. Dystroglycan, (Figure legend continues.) 
with commercial planar multielectrode arrays (Multichannel Systems; Bölinger and Gollisch, 2012). Retinae of dark-adapted $\mathrm{CAST}^{+/+}$and $\mathrm{CAST}^{-1-}$ mice of either sex were isolated from the eye cup under infrared illumination, cut in half, and placed ganglion cell side down on an array of either 252 or 60 electrodes. During recordings, the retina was continuously superfused with Ames' medium, buffered with 22 mм $\mathrm{NaHCO}_{3}$ and $5 \% \mathrm{CO}_{2} / 95 \% \mathrm{O}_{2}, \mathrm{pH} 7.4$, and maintained at $33^{\circ} \mathrm{C}$. Spike times of individual ganglion cells were determined from the recorded voltage traces by a custom-made spike sorting program, based on a Gaussian mixture model (Pouzat et al., 2002). Only units whose clusters were well separated and that showed a clear refractory period were used in the analysis. The analysis included 28 ganglion cells recorded from three $C A S T^{-/-}$animals and 35 ganglion cells recorded from three $\mathrm{CAST}^{+/+}$animals.

To visually stimulate the retina, the screen of a miniature white-light OLED monitor (eMagin) was focused with a telecentric lens (Edmund Optics) onto the photoreceptor layer, covering the recorded piece of retina. $\mathrm{Vi}$ sual stimulation consisted of 20 cycles of a sequence of brief steps in light intensity, each lasting $200 \mathrm{~ms}$, presented at $0.5 \mathrm{~Hz}$ on a background of white light at $94 \mu \mathrm{W} / \mathrm{m}^{2}$ in the scotopic range, corresponding to an average isomerization rate of $55 \mathrm{R}^{\star} / \mathrm{rod} / \mathrm{s}$. The light intensity steps were presented alternately with positive and negative contrast in increasing order of magnitude, using the following contrast values (measured in percentage change from background luminance): $2.5,4.5,6.5,10,13$, 20,27 , and 40 .

For each recorded cell, the contrast threshold was determined in the following way. For each step, the number of spikes in a $200 \mathrm{~ms}$ window, starting $50 \mathrm{~ms}$ after onset, was compared with the spike number in the $200 \mathrm{~ms}$ before the contrast step. The detection probability was then estimated from a two-alternative forced-choice paradigm as the probability that higher spike count was obtained during the step. The threshold was obtained as the contrast level for which the detection probability reached $80 \%$, as determined from the fit of a Weibull cumulative distribution function to the contrast dependence of the detection probability. For each cell, only data from steps of either positive or negative contrast were used, depending on whether the cell was On or Off type, respectively.

Measuring visual acuity and contrast sensitivity. Visual acuity was assessed in five $\mathrm{CAST}^{+/+}$and five $\mathrm{CAST}^{-/-}$mice of either sex (all animals were $90 \mathrm{~d}$ of age) using the recently developed virtual-reality optomotor system (Prusky et al., 2004). Briefly, freely moving animals were exposed to moving sine wave gratings of various spatial frequencies and contrasts and reflexively tracked the gratings by head movements as long as they could see the gratings. Spatial frequency at full contrast and contrast at six different spatial frequencies were varied by the experimenter until the threshold of tracking was determined. Because only motion in the temporal-to-nasal direction evokes tracking, it is possible to measure thresholds and contrast functions for both eyes separately by reversing the direction of the moving gratings (Douglas et al., 2005). The threshold

$\leftarrow$

(Figure legend continued.) thought to outline the postsynaptic invagination of bipolar cell dendrites, is present in all genotypes, as is the postsynaptic metabotropic glutamate receptor mGluR6. However, the postsynaptic $\mathrm{Ca}^{2+}$ channel subunit Cacna1s colocalizes with mGluR6 and dystroglycan staining only in $\mathrm{CAST}^{+/+}$and $\mathrm{CAST}^{-/-}$mice but not in $\mathrm{Bsn}^{\Delta e x 4 / 5}$ mutants. Scale bar, $5 \mu \mathrm{m}$. for grating acuity and contrast thresholds at the following six spatial frequencies were measured: 0.031, 0.064, 0.092, 0.103, 0.192, and 0.272 cycles/degree $\left(\mathrm{cyc} /{ }^{\circ}\right)$. Contrast sensitivity was calculated at each spatial frequency as a Michelson contrast from the screen luminance (maximum - minimum $) /($ maximum + minimum $)$ and the reciprocal of the threshold (black mean, $0.22 \mathrm{~cd} / \mathrm{m}^{2}$; white mean, $152.13 \mathrm{~cd} / \mathrm{m}^{2}$ ). All intergroup comparisons were done by Student's two-tailed $t$ test. The levels of significance were set as ${ }^{\star} p<0.05,{ }^{* *} p<0.01$, and ${ }^{* *} p<0.001$. Data are represented as means \pm SEM.

\section{Results}

\section{Deletion of the mouse CAST gene}

To gain insight into the role of CAST for defining size, structure, and function of the active zone, we generated a loss-of-function mouse mutant for the CAST gene (Fig. 1). CAST ${ }^{-/-}$mice were generated by replacement of the first exon by conventional homologous recombination in mouse ES cells (Fig. $1 A-C$ ). This manipulation led to absence of detectable CAST immunoreactive protein in WBs of $C A S T^{-/-}$retinal extracts when compared with extracts from $\mathrm{CAST}^{+/+}$animals (Fig. 1D). CAST protein levels were intermediate in heterozygous animals (data not shown). In addition, the expression level of ELKS was significantly upregulated by $\sim 1.7$-fold during CAST deletion, whereas that of the ribbon synapse marker RIBEYE (CtBP2) or Tubulin was not. CAST immunoreactivity seen in $C A S T^{+/+}$animals in the synaptic layers (Fig. $1 E$ ) — the OPL and inner plexiform layer (IPL)was absent in $\mathrm{CAST}^{-/-}$animals (Fig. $1 \mathrm{~F}$ ). 
A

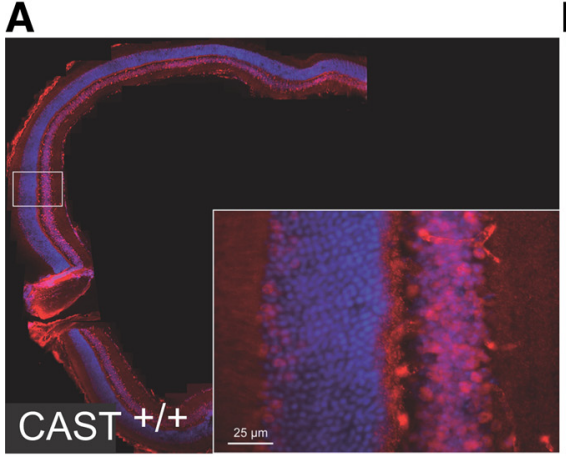

B

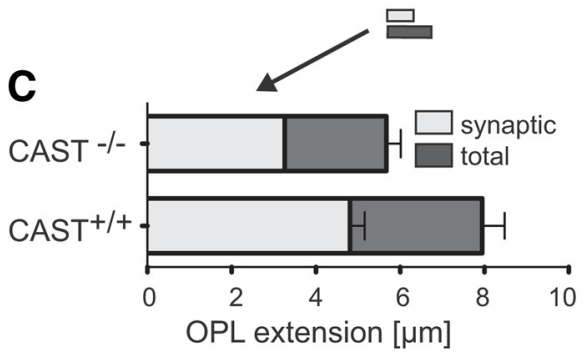

$\mathbf{F}$

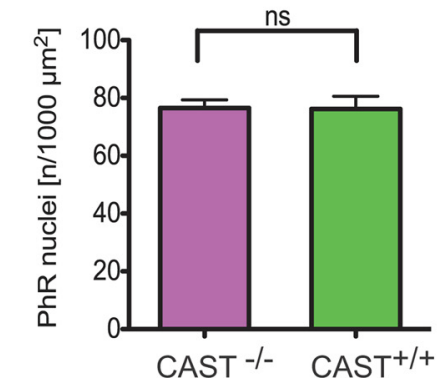

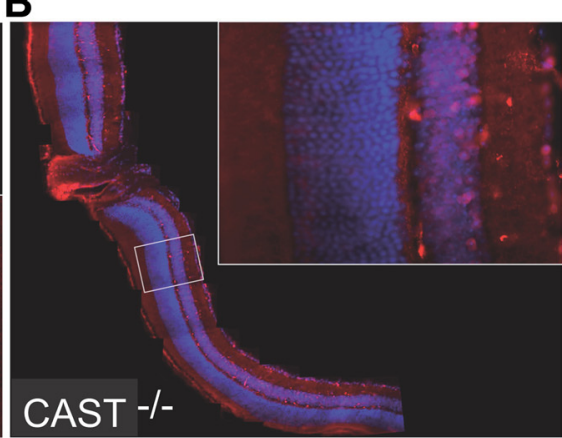

D

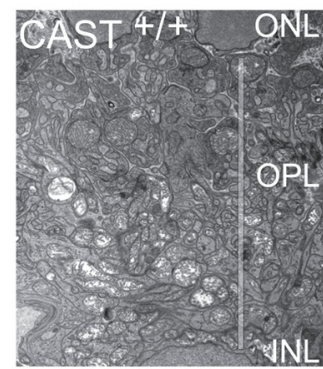

E

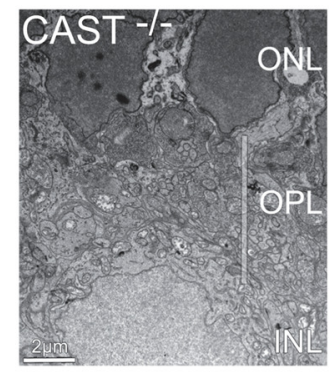

Figure 4. The size of the $O \mathrm{PL}$ is reduced in $\mathrm{CAST}^{-/-}$mice. $\boldsymbol{A}, \boldsymbol{B}$, Retinae from $\mathrm{CAST}^{+/+}(\boldsymbol{A})$ and $\mathrm{CAST}^{-/-}(\boldsymbol{B})$ mice were mounted with preserved orientation, and cryostat sections were cut vertically through a plane of the optic nerve. Sections were stained for nuclei (blue, DAPl; some nuclei expressing the transcriptional coactivator CtBP2 stain red with CtBP2 antibody) and ribbons (red, RIBEYE, stains as an alternative gene product from the CtBP2 gene ribbons with the CtBP2 antibody). We measured the size of the synaptic (CTPB2-stained) and total area of the OPL in $5 \mu \mathrm{m}$ steps from the optic nerve along the retina to calculate mean size estimates for both extensions in the different genotypes. Both the synaptic and the total OPL extension were reduced in $C A S T^{-/-}$mice compared with $C A S T^{+/+}$mice $(C ; n=3$ animals per genotype, $>120$ data points per animal; mean \pm SEM, $t$ test, $p=0.023$ total, $p=0.011$ synaptic). This finding was confirmed by electron micrographs of $\mathrm{CAST}^{+/+}(\boldsymbol{D})$ and $\mathrm{CAST}^{-/-}(\boldsymbol{E})$ OPL. The reduced OPL size was not attributable to loss of photoreceptors because the number of photoreceptor nuclei did not differ between genotypes as calculated from areas spanning the whole ONL ( $\boldsymbol{F} ; 3$ areas per animal; mean \pm SEM, $t$ test, $p=0.023$ total, $p=0.011$ synaptic). ad, Arciform density. Scale bars: $\boldsymbol{A}, \boldsymbol{B}, 25 \mu \mathrm{m} ; \boldsymbol{D}, \boldsymbol{E}, 2 \mu \mathrm{m}$.

\section{Ultrastructure of rod photoreceptor synapses is primarily maintained despite disruption of CAST}

Rod photoreceptor spherules possess a single large cytomatrix structure called synaptic ribbon. It lines the active zone and bends along several postsynaptic elements that invaginate into the presynaptic terminal (Fig. 1I). These postsynaptic elements comprise receptive dendrites from vertically transmitting bipolar cells and processes of horizontal cells that mediate feedback between photoreceptors. Electron microscopic analysis did not show obvious effects on rod photoreceptor synapse architecture in $C A S T^{-/-}$mice at the single-section level (Fig $\left.1 G, H\right)$. This contrasts with the robust disruption of synaptic structure on inactivation of the CAST paralog in Bruchpilot in Drosophila, which goes along with a complete loss of the electron-dense cytomatrix structures called T-bars (Kittel et al., 2006).

Ribbons were found anchored to the active zones in rod spherules, deviating from the finding in Bassoon loss-of-function mutants (Dick et al., 2003; tom Dieck et al., 2005). There, the ribbons were no longer anchored to the active zone but floated in the cytoplasm, and an arciform density was not visible. CAST, as a known interaction partner of Bassoon, was a candidate to link Bassoon to the arciform density and active zone plasma membrane (tom Dieck et al., 2005). However, the presence of the arciform density and anchored ribbons in CAST-deficient photoreceptors indicate that, although it may contribute, CAST is not essential for localizing Bassoon and the ribbon at the active zone. The presynaptic cone pedicles also displayed anchored ribbons (data not shown), but were not further investigated because of the low fraction of cones in the mouse retina (3\%; Peichl, 2005).

\section{Molecular anatomy of rod ribbon synapses is primarily maintained}

Next, we addressed the molecular architecture of the rod synapse arrangement by light microscopy (tom Dieck et al., 2005). Comparing CAST ${ }^{-/-}$synapses with those of $C A S T^{+/+}$for the immunofluorescence of various presynaptic and postsynaptic markers, we found only subtle if any alterations, much different from those in $B s n^{\Delta e x 4 / 5}$ mutants. In $B s n^{\Delta e x 4 / 5}$ mutants, ribbons floated in the presynaptic cytoplasm and lost the typical horseshoeshaped form, the presynaptic arciform density disassembled, and the postsynaptic accumulation of the $\mathrm{Ca}^{2+}$ channel pore-forming unit Cacnals was no longer detected (Fig. 2). Instead, the synapses of $\mathrm{CAST}^{-/-}$mice showed a conserved arrangement of markers of the active zone plasma membrane and the arciform density relative to the anchored synaptic ribbon. Specifically, whereas the integral ribbon markers Piccolo and RIBEYE colocalized in all three genotypes, the ribbon fluorescence was elongated and bent in $\mathrm{CAST}^{-/-}$rod photoreceptors similar to, but not identical to, $C A S T^{+/+}$rather than punctuate as seen in the $B s n^{\Delta e \times 4 / 5}$ mutants. Moreover, the arciform density protein RIM2 was distributed along the concave inside of the RIBEYE label much as seen in $\mathrm{CAST}^{+/+}$mice, whereas RIM2 staining was reduced and only sometimes present in small hotspots with no clear orientation toward RIBEYE in $B s n^{\Delta e x 4 / 5}$ mutants. A very similar pattern was seen also for the active zone L-type $\mathrm{Ca}^{2+}$ channel $\mathrm{Ca}_{\mathrm{V}} 1.4$ (Cacnalf). Markers for the postsynaptic invagination - dystroglycan and mGluR6-were present in all genotypes in contrast to the postsynaptic calcium channel Cacnals that was not stabilized at the postsynaptic sites of $B s n^{\Delta e x 4 / 5}$ mice. We conclude that the presynaptic and postsynaptic molecular anatomy was essentially intact in $\mathrm{CAST}^{-{ }^{--}}$mice.

\section{Reduced active zone size in $C A S T^{-/-}$mice}

Although we found essentially intact presynaptic and postsynaptic organizations of rod ribbons in the OPL of $C A S T^{-/-}$mice, the 
ribbons appeared less elaborate when compared with $\mathrm{CAST}^{+/+}$(Figs. 2, 3A). To assess this quantitatively, we measured the lateral extension of the ribbons in maximum projections of confocal sections as a proxy of active zone length (Fig. $3 A, B$ ). We note that we analyzed all ribbons regardless of their orientation for both genotypes. Therefore, our "apparent ribbon length" underestimates the true ribbon length and, hence, active zone size. For this analysis, we used confocal images of cryosections obtained from a stacked pair of $\mathrm{CAST}^{+/+}$and $C A S T^{-/-}$retinae, which had been processed together on the same slide, stained, and imaged with identical microscope settings (Fig. $3 B$ ). Indeed, we observed a significant reduction of mean apparent ribbon length in $C A S T^{-/-}$mice (37\% reduction, $1.03 \pm 0.02 \mu \mathrm{m}$ for $\mathrm{CAST}^{-/-}$vs $1.61 \pm 0.02 \mu \mathrm{m}$ for $C A S T^{+/+} ; p<0.001$, paired $t$ test). Given the close relationship of the immunofluorescence of active zone and arciform density markers with the ribbons (Fig. 2), we take the reduced ribbon extent to indicate a reduction in active zone size. Indeed, analysis of $\mathrm{Ca}_{\mathrm{V}} 1.4$ (Cacnalf) immunoreactivity by integration of twodimensional Gaussian fits to the background-corrected immunofluorescence $[23,648 \pm 11,217$ a.u. (mean \pm $\mathrm{SD}, n=181$ active zones from 2 animals) for $C A S T^{-/-}$vs 33,760 \pm 13866 a.u. (mean $\pm \mathrm{SD}, n=225$ active zones from 2 animals) for $C A S T^{+/+} ; p<$ 0.001 , Wilcoxon's rank test] indicated a reduction of the number of presynaptic $\mathrm{Ca}^{2+}$ channels similar to that found for ribbon length (30\%).

The mean density of vesicles attached to the ribbon determined from random EM sections through the ribbon synapse was not significantly different between $\mathrm{CAST}^{-/-}$and $\mathrm{CAST}^{+/+}$(Fig. 3C,D). Together, the unaltered vesicle density with the reduced lateral extent of the ribbon to 0.6 of $C A S T^{+/+}$, we assume that the number of ribbon-associated vesicles of $\mathrm{CAST}^{-/-}$synapses was reduced to $\sim 0.6$ that of $C A S T^{+/+}$synapses. In conclusion, disruption of CAST causes a reduced size of rod photoreceptor active zones, which otherwise seemed molecularly and structurally unaltered.

\section{The width of the OPL is reduced in the} $\mathrm{CAST}^{-/-}$mutant

In addition to the reduced size of rod active zones, we also found a reduced vertical extension of the OPL in the CAST ${ }^{-/-}$ retina (Fig. 4). Counts of photoreceptor nuclei in the ONL were comparable with $C A S T^{+/+}$(Fig. $\left.4 A, B, F\right)$ so that photoreceptor cell loss is unlikely to account for the reduced width of the OPL.

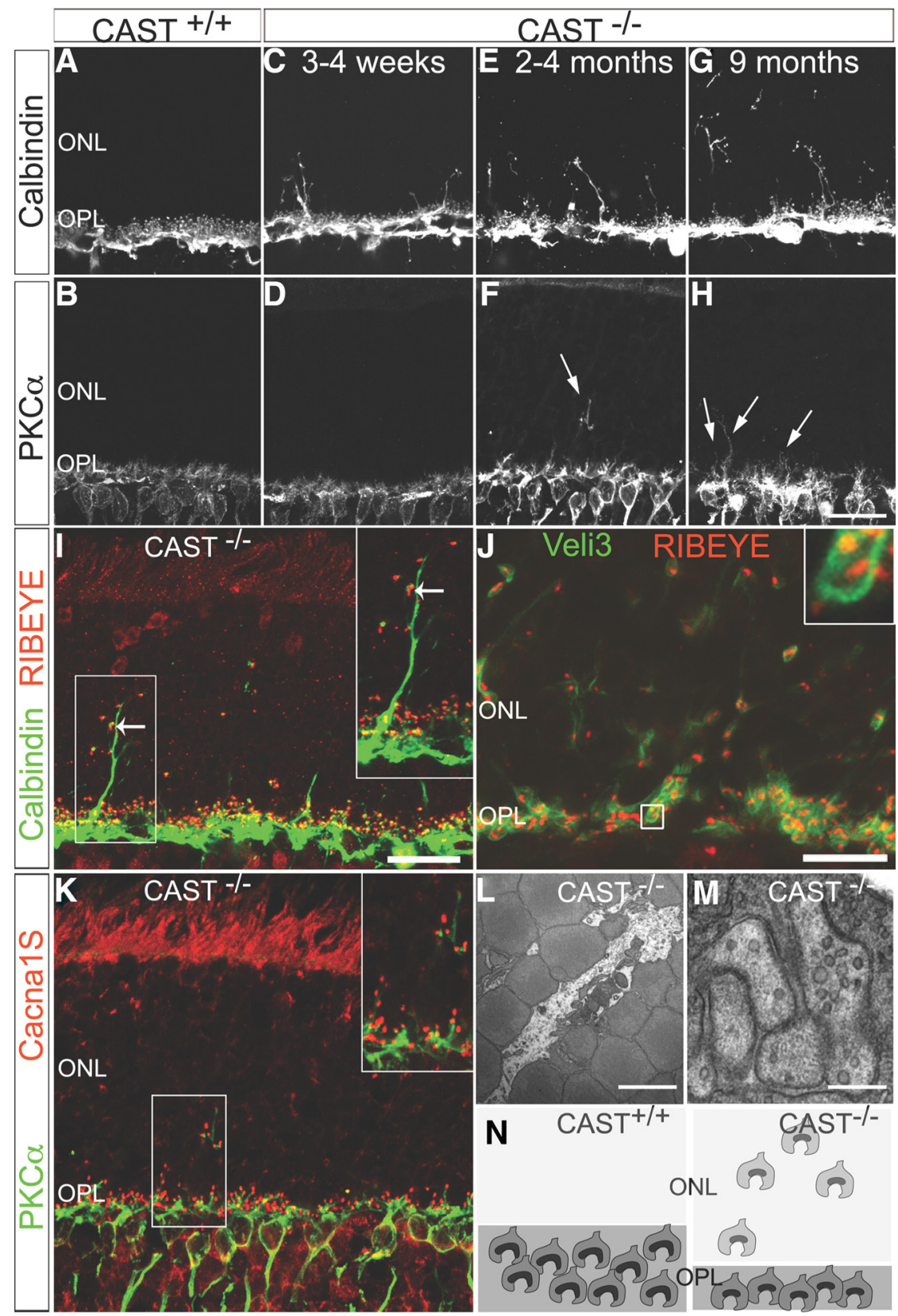

Figure 5. Ectopic synapses are found in the $0 \mathrm{NL}$ of $C A S T^{-/-}$mice. $\boldsymbol{A}-\boldsymbol{H}$, Confocal micrographs of vertical retina sections stained for horizontal cells (Calbindin) or rod bipolar cells (PKC $\alpha$ ) that are postsynaptic to rod photoreceptors. The micrographs show that the confinement of the postsynaptic endings of these cell types to the OPL seen in $C A S T^{+/+}(A, B)$ is compromised in the CAST ${ }^{-/-}$ retina in which both cell types show an age-dependent sprouting into the ONL that usually is free of bipolar and horizontal cell processes $(\boldsymbol{A}-\boldsymbol{H})$. Horizontal cell sprouting is detected earlier than bipolar cell sprouting $(\boldsymbol{C}, \boldsymbol{D})$. I- $\boldsymbol{K}$, Confocal micrographs of vertical retina sections stained for cell types and ribbon synaptic subcompartment markers reveal that horizontal and bipolar cell sprouts in the ONL are decorated with synapses. Calbindin-positive horizontal cell tips colocalize with the ribbon marker RIBEYE (I) and RIBEYE immunoreactivity is surrounded by the ribbon presynaptic terminal membrane marker Veli3 ( $($ ). In addition, bipolar cell dendritic tips display the ribbon postsynaptic marker Cacna1s $(\boldsymbol{K})$. Insets show close-ups of boxed areas. $\boldsymbol{L}, \boldsymbol{M}$, Electron micrographs of $\mathrm{CAST}^{-1-}$ retinas showing examples of an ectopic neurite $(\boldsymbol{L})$ and an ectopic ribbon synapse $(\boldsymbol{M})$ in the ONL. $\boldsymbol{N}$, Schematic drawing of the characteristics of the CAST ${ }^{-1-}$ OPL and ONL in contrast to $C A S T^{+/+}$outer retina to illustrate the features of the CAST $^{-1-}$ phenotype: thinning of the OPL area could be explained by fewer synapses, displacement of synapses to the ONL, and/or smaller synapses. In the $\mathrm{CAST}^{-/-}$ribbon synaptic complexes, the synapse architecture is preserved but the length of the active zone is shorter than in $\mathrm{CAST}^{+/+}$. Scale bars: in $\boldsymbol{H}$ for $\boldsymbol{A}-\boldsymbol{H}$ and in $\boldsymbol{I}$ for $\boldsymbol{I}, \boldsymbol{K}, 20 \mu \mathrm{m} ; \boldsymbol{J}, 10 \mu \mathrm{m} ; \boldsymbol{L}, 2 \mu \mathrm{m} ; \boldsymbol{M}, 0.2 \mu \mathrm{m}$.

We measured the width of the OPL in the two genotypes as the distance from the innermost border of the photoreceptor nuclei to the start of the nuclei of bipolar and horizontal cells in comparable locations with respect to the optic nerve to account for regional differences in layer size throughout the retina. This mea- 

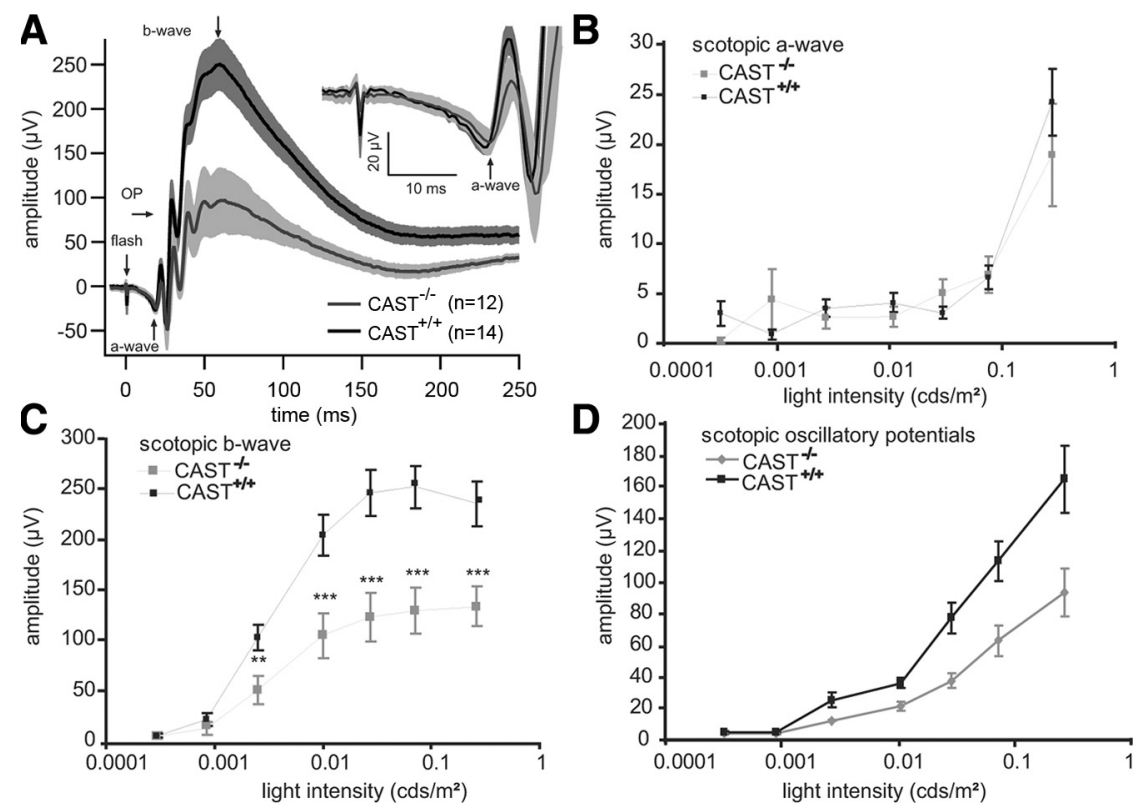

Figure 6. ERG b-wave and oscillatory potentials are reduced in $C_{A S T^{-1-}}$ mice. Dark-adapted (scotopic) ERGs were recorded in CAST $^{+/+}\left(n=12\right.$, black) and CAST ${ }^{-/-}(n=12$, gray) mice in response to light flashes of $0.1,1$, and 5 ms duration. $A$, Average ERG traces obtained during application of a 5-ms-long, $0.295 \mathrm{~cd} / \mathrm{m}^{2}$ stimulus (CAST ${ }^{+/+}$mean and SEM: black line, dark gray area; $\mathrm{CAST}^{-1-}$ mean and SEM: gray line and light gray area). The discernible signal components are indicated by arrows (OP, oscillatory potentials), as is the timing of the light flash. The inset displays the early phase, including the a-wave, at higher resolution: overlap of CAST $^{+/+}$and $C A S T^{-/-}$data. $\boldsymbol{B}-\boldsymbol{D}$, Amplitudes of the a-wave $(\boldsymbol{B})$, b-wave $(\boldsymbol{C})$, and oscillatory potentials $(\boldsymbol{D})$ plotted as a function of increasing light stimulus intensities. The amplitudes of the a-wave remained intact in $C A S T^{-/-}$mice compared with $\mathrm{CAST}^{+/+}$, whereas b-wave and oscillatory potentials showed significantly reduced amplitudes in the $\mathrm{CAST}^{-/-}$mice.

sure covered both photoreceptor boutons with the invaginating postsynaptic elements of bipolar and horizontal cells and the non-invaginating part of the postsynaptic plexus of horizontal and bipolar cell dendrites and showed a reduced OPL extension in the $C A S T^{-/-}$retina (Fig. $4 C$ ). To judge whether this was attributable to the reduction of the synaptic area or to a reduction in the non-invaginating part of the postsynaptic plexus, we measured the width of the area occupied by photoreceptor ribbons (Fig. $4 A, B$, red). As for the whole OPL, we found a significant reduction in the area occupied by presynaptic profiles likely attributable to a smaller size of the synapses and terminals as well as to the retraction of several synapses into the ONL (see below). Electron micrographs confirmed the findings obtained by light microscopy (Fig. 4). The distance between photoreceptor nuclei and horizontal/bipolar cell nuclei was reduced, and less presynaptic profiles were seen in the OPL. The analysis did not reveal a reduction of the postsynaptic plexus size.

\section{Postsynaptic sprouting and aberrant synapse formation in the ONL}

Sprouting of postsynaptic elements into the ONL with aberrant formation of synapses has been found in retinae of mouse mutants with impaired synaptic transmission (Haeseleer et al., 2004; Mansergh et al., 2005; Chang et al., 2006; Specht et al., 2007, 2009). Therefore, we investigated whether this was also the case in $C A S T^{-1-}$ mice and could potentially contribute to the reduction of OPL width. Indeed, we observed that some horizontal cells extended processes into the ONL already at 3-4 weeks of age shortly after photoreceptor synapse maturation is completed in normal mice (Fig. 5A,C). At this time, bipolar cell dendritic arborizations were restricted to the OPL (Fig. $5 B, D$ ). The number and extent of horizontal cell sprouts increased with age (Fig.
$5 C, E, G)$. These horizontal sprout endings in $\mathrm{CAST}^{-/-}$animals contacted CtBP2/ RIBEYE immunofluorescent spots in the ONL (Fig. 5I). This ectopic CtBP2/RIBEYE immunoreactivity in the ONL was associated with Veli3, a marker that outlines photoreceptor presynaptic terminals (Fig. 5J). Although not observed at 3-4 weeks of age, bipolar cell dendrites were detected in the CAST ${ }^{-/-}$ONL of animals of 2 months and older, in which they contacted multiple presynaptic CtBP2/ RIBEYE-positive sites (Fig. $5 B, D, F, H, K$ ). Electron micrographs of $C A S T^{-/-}$retinas confirmed the presence of ectopic neurites (Fig. 5L) and an ectopic ribbon synapse (Fig. 5M) in the ONL. This phenomenon probably contributes to the reduced OPL size and is sketched in the diagram of Figure $5 \mathrm{~N}$.

\section{Lack of CAST impairs light encoding at the photoreceptor to bipolar cell synapses}

Rod-dependent (dark-adapted) vision was tested in anesthetized $C A S T^{-/-}$and $C A S T^{+/+}$mice by recordings of the ERG using Ganzfield light-flash stimulation (see Materials and Methods). ERGs reflect global electrical responses of the retina to a series of light flashes of increasing intensities (Fig. 6A). We analyzed the three main signal components: (1) the a-wave, reflecting photoreceptor ionic currents; (2) the b-wave, reflecting primarily the activity of ON bipolar cells; and (3) the oscillatory potentials, thought to be generated by the combined activity of GABAergic and glycinergic amacrine cells in the IPL. The a-waves were comparable between $C A S T^{+/+}$and $C A S T^{-1-}$ mice (Fig. $6 A, B$ ), indicating normal phototransduction, which is consistent with our finding of a normal photoreceptor density in the $C A S T^{-/-}$retinae (Figs. 4, 5). However, we found reduced amplitudes of the b-wave (Fig. 6C) and the oscillatory potentials (Fig. 6D). This indicated impaired synaptic transmission from photoreceptors to bipolar cells and potentially also downstream. The latency of the waves (implicit times) and the frequencies inherent to the oscillatory potentials remained unaltered (data not shown).

\section{Lack of CAST impairs contrast sensitivity and visual acuity}

To test how the altered structure of photoreceptor terminals affected the signals emerging from the retina, we recorded spikes from retinal ganglion cells, the output cells of the retina, under stimulation with contrast steps of increasing size. For each cell, we determined the contrast threshold required to detect the stimulus with $80 \%$ correct, based on comparing the spiking activity during the contrast steps to the activity just before the step (Fig. 7A). Ganglion cells from $C A S T^{-/-}$retinae showed a significantly higher contrast threshold compared with $C A S T^{+/+}$retinae (Fig. $7 B ; p<0.01$ Mann-Whitney $U$ test), indicating that stronger visual signals were necessary in $\mathrm{CAST}^{-1-}$ animals to reliably activate the ganglion cells.

Next, we turned to optometry for a behavioral assay of vision in $C A S T^{-/-}$mice. Contrast sensitivity of $\mathrm{CAST}^{-/-}$mice was clearly reduced when compared with the performance of the $\mathrm{CAST}^{+/+}$animals at all six measured spatial frequencies (Fig. 
$8 A)$. Statistical analyses confirmed that the genotype had an impact on contrast sensitivity that was highly significant $(p<0.001$ for all six comparisons, $t$ test with Bonferroni's correction). For instance, at a spatial frequency of $0.064 \mathrm{cyc} /{ }^{\circ}, C A S T^{-/-}$mice had a contrast sensitivity of $7.6 \pm 0.1$ (corresponding to $13.5 \%$ contrast), whereas $\mathrm{CAST}^{+/+}$littermates had a contrast sensitivity of $16.5 \pm 0.7$ (or $6 \%$ contrast). At a spatial frequency of $0.031 \mathrm{cyc} /{ }^{\circ}$, the contrast sensitivity values for $\mathrm{CAST}^{-/-}$mice and $\mathrm{CAST}^{+/+}$ mice were $2.9 \pm 0.04$ (corresponding to $35 \%$ contrast) and $3.9 \pm$ 0.08 (or $26 \%$ contrast), respectively. Thus, contrast sensitivity in $C A S T^{-/-}$mice was reduced by a factor of 1.3-2.3 (at the different spatial frequencies) compared with $C A S T^{+/+}$mice, indicating that $C A S T^{-/-}$mice need 1.3- to 2.1-fold higher contrasts of visual stimuli to trigger the optomotor reflex. Contrast sensitivity curves of both genotypes peaked at a spatial frequency of 0.064 $\mathrm{cyc}^{\circ}{ }^{\circ}$, as described previously for C57BL/6 mice (Prusky et al., 2004). Finally, we tested the visual acuity of $C A S T^{-/-}$mice, which amounted to $0.33 \pm 0.002 \mathrm{cyc} /{ }^{\circ}$ in each eye and was lower than that found in $C A S T^{+/+}$animals $\left(0.38 \pm 0.004 \mathrm{cyc}^{\circ}, p<\right.$ $0.001, t$ test). There was no difference between left and right eyes for both genotypes ( $p>0.05$ for both comparisons, $t$ test). Both visual acuity and contrast sensitivity of $C A S T^{-/-}$mice were less strongly impaired than in Bsn mutant mice (Goetze et al., 2010). In conclusion, recordings from retinal ganglion cells and optometry both revealed impaired visual processing in $C A S T^{-/-}$mice.

\section{Discussion}

This study revealed a role for the presynaptic scaffold protein CAST in determining the active zone size at rod photoreceptor ribbon synapses. Different from the global disruption of the active zone seen during genetic manipulation of the scaffold protein Bassoon, inactivation of the CAST gene, beyond the active zone size reduction, did not detectably alter the presynaptic and postsynaptic organization. The morphological change went along with an impairment of synaptic encoding of visual stimuli and consecutively reduced contrast sensitivity and visual acuity.

\section{Reduced active zone size but preserved molecular} synapse anatomy

The mechanisms determining the size of an active zone are not well understood. Recent evidence suggests that the molecules involved in early formation of active zones, such as liprins and CAST/ELKS/ERC proteins, also contribute to or correlate with changes in active zone size in mature synapses (Zhen and Jin, 1999; Kaufmann et al., 2002, p 2; Olsen et al., 2005; Dai et al., 2006; Astigarraga et al., 2010; Lazarevic et al., 2011). Active zone size can change over different timescales from minutes (Matz et al., 2010) to hours (SpiwoksBecker et al., 2004; Hull et al., 2006) to days (Lazarevic et al., 2011), accompanying changes of synaptic activity and the circadian cycle. The hierarchy of regulation is likely to differ between synapse formation and structural plasticity and among different synapses. Active zone size in sensory cells may additionally be governed by expression levels (Sheets et al., 2011) and trafficking of RIBEYE (Spiwoks-Becker et al., 2004). Here we took advantage of the large size of the rod photoreceptor ribbon synapse to explore
A
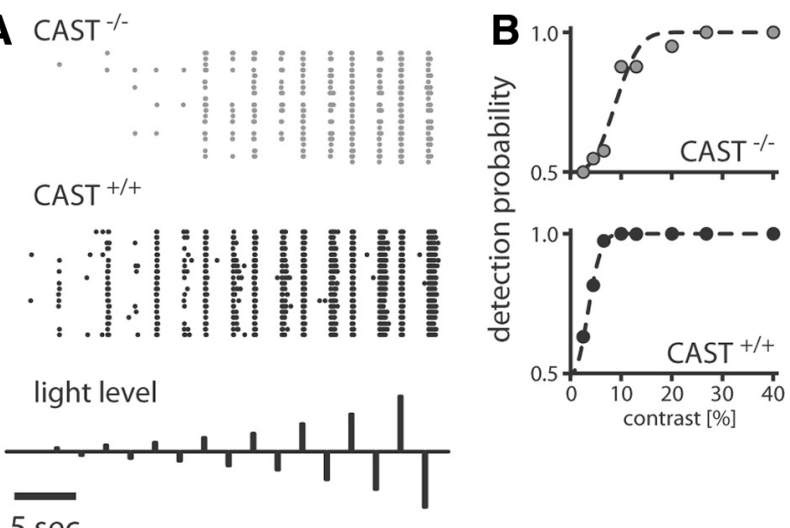

$5 \mathrm{sec}$

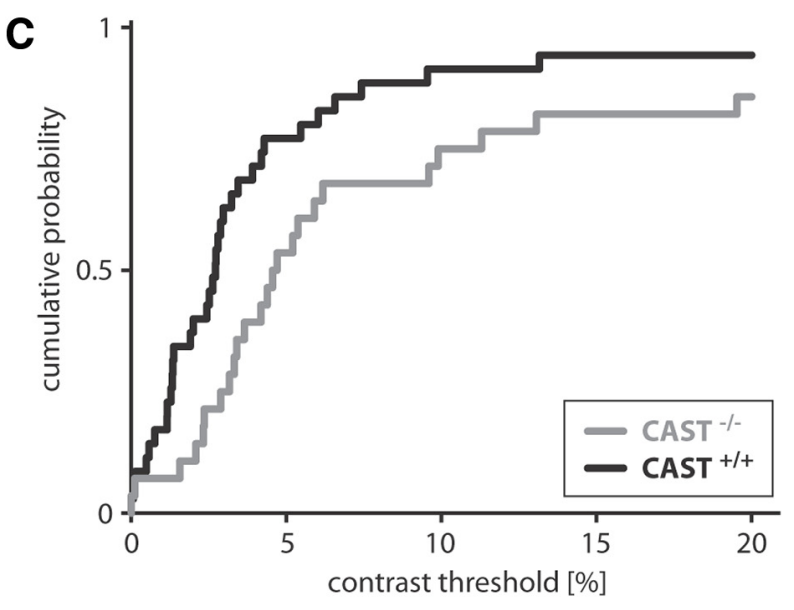

Figure 7. Contrast sensitivity of retinal ganglion cells. A, Spike responses of two representative On-type ganglion cells from a CAST ${ }^{-/-}$and CAST $^{+/+}$retina, respectively. The raster plots (left) show individual spike times for several trials of the sequence of steps in light intensity (shown on the bottom). The cells fire in response to brief increments of light intensity at high enough contrast and also show (delayed) responses to the offsets of light decrements. $\boldsymbol{B}$, Detection probability at each applied contrast level for the two cells of $\boldsymbol{A}$. The dashed lines show fitted Weibull cumulative distribution functions. The $\mathrm{CAST}^{+/+}$cell reaches high detection probability at lower contrast levels and therefore has a lower contrast threshold. C, Cumulative probabilities of estimated contrast thresholds for $\mathrm{CAST}^{-/-}$(gray, $\left.n=28\right)$ and CAST ${ }^{+/+}$(black, $n=35)$ ganglion cells.

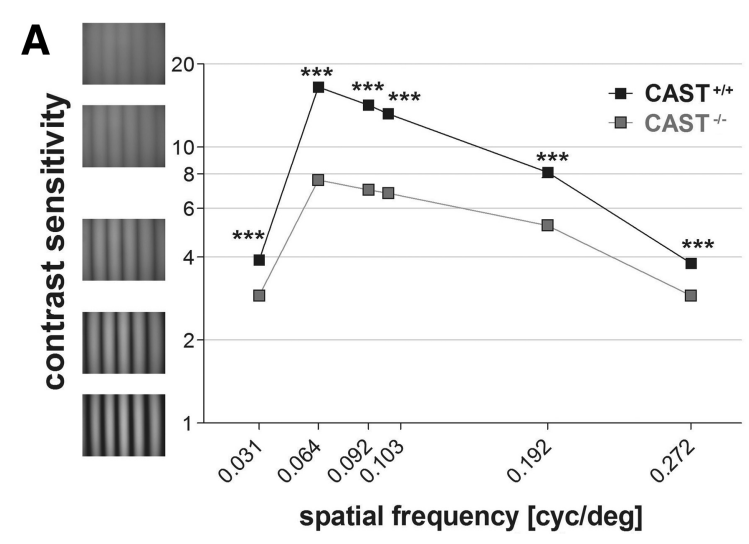

B

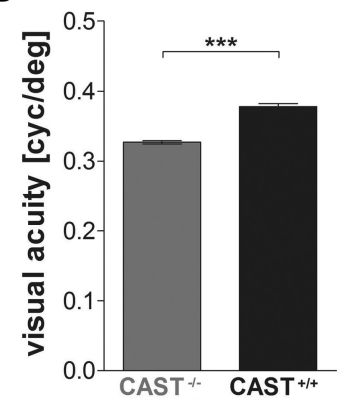

Figure 8. Contrast sensitivity and visual acuity of $C A S T^{-/-}$and $C A S T^{+/+}$mice measured with the virtual-reality optomotor system. Average and SEM values are plotted for both genotypes. $\boldsymbol{A}$, Contrast sensitivity was measured at six different spatial frequencies. Contrast sensitivity of CAST $^{-/-}$mice was reduced by a factor of 1.3 to 2.3 compared with their CAST ${ }^{+/+}$littermates. Maximal contrast sensitivity was achieved at a spatial frequency of $0.064 \mathrm{cyc} /{ }^{\circ}$ and was $7.4 \pm 0.1 \mathrm{in} \mathrm{CAST}{ }^{-/-}$compared with $16.7 \pm 0.7$ in CAST ${ }^{+/+}$mice. At all six spatial frequencies, contrast sensitivity was significantly lower in CAST $^{-/-}$compared with CAST ${ }^{+/+}$mice $(p<0.001$ for all comparisons, $t$ test with Bonferroni's correction). $\boldsymbol{B}$, Visual acuity of CAST ${ }^{+/+}$mice was $0.38 \pm 0.004 \mathrm{cyc} /{ }^{\circ}$ compared with $0.33 \pm 0.002 \mathrm{cyc} /{ }^{\circ}$ in CAST $^{-1-}$ mice. The difference in visual acuity was statistically significant $(p<0.001, t$ test). 
the effect of CAST/ERC2 deletion. Synapses were formed, showed a generally preserved molecular presynaptic and postsynaptic organization, and were functional. It is conceivable that ELKS, which is also expressed by rod photoreceptors (Deguchi-Tawarada et al., 2006) and was upregulated in $C A S T^{-/}$retinae, at least partially compensated for a role of CAST in synapse formation and maintenance. However, loss of CAST function resulted in a reduction of rod photoreceptor active zone size. This, to our knowledge, is the first direct demonstration of a role of CAST in defining active zone size. We hypothesize that CAST, as a molecular scaffold with multiple binding sites for other cytomatrix proteins, contributes to the proper lateral assembly of the ribbon and the arciform density to establish and/or stabilize a full-length active zone. Other candidates mediating stabilization might be liprin- $\alpha$ s (Dai et al., 2006) and in particular liprin- $\alpha 4$, because it shows an overlapping expression pattern with other CAZ proteins at rod photoreceptor synapses. It seems, however, not to be confined to the active zone (Zürner et al., 2011). Interestingly, often two RIBEYE- and Bassoon-containing precursor spheres - prefabricated building blocks that appear during rod ribbon synapse formation-are found in rod terminals before membrane attachment and maturation of the rod ribbon complex (Regus-Leidig et al., 2009). CAST could well serve to connect those building blocks via interaction with Bassoon to stabilize the complex. In the $B s n^{\Delta e x 4 / 5}$ mutant, RIBEYE-containing precursor spheres reach the presynaptic rod terminal but never become properly anchored to the active zone, thus also fitting with this hypothesis (Regus-Leidig et al., 2010). Whether CAST connects preformed building blocks or is required to directly stabilize a large presynaptic arciform density and via interaction with Bassoon recruits large amounts of RIBEYE to form the characteristic rod ribbons of large size and horseshoe shape has to be examined in future experiments.

\section{Functional impairment}

Scotopic vision mediated by rod photoreceptors was probed by ERG in $\mathrm{CAST}^{-/-}$mice. Consistent with the intact morphology and number of rods, the a-wave was not altered, indicating normal transduction. Therefore, we attribute the reduction of the b-wave amplitude to an impaired excitatory neurotransmission at the ribbon synapses of the outer retina. This is consistent with the previous data that CAST is required for excitatory neurotransmission in cultured rat superior cervical ganglion neurons (Takao-Rikitsu et al., 2004). However, it has been reported recently that CAST is involved in inhibitory neurotransmission, but not in excitatory neurotransmission, in mouse hippocampus, revealed by analyzing CAST mutant mice (Kaeser et al., 2009). Currently, we cannot explain this discrepancy, but it may reflect different requirements of the active zones for CAST.

The observed halving of the maximal scotopic b-wave amplitude corresponds roughly to the $37 \%$ reduction of the apparent rod active zone size. The normal latency of the b-wave argues against a major increase in synaptic delay, because it might occur if $\mathrm{Ca}^{2+}$ influx-exocytosis coupling was altered. Comparison of the retinal phenotypes of CAST and Bassoon loss-of-function mouse mutants suggests much milder structural and functional deficits of the retina during disruption of CAST. Therefore, and because the molecular organization of the presynaptic and postsynaptic compartments remained apparently unaltered in $C A S T^{-/-}$mice, we consider the possibility that the functional impairment primarily reflects the reduced active zone size of rod photoreceptor cells. We speculate that the number of release sites, i.e., docking sites for vesicles in proximity to $\mathrm{Ca}^{2+}$ channels at the presynaptic membrane (total RRP if fully occupied), scales with the size of the active zone. Indeed, we found the synaptic $\mathrm{Ca}_{\mathrm{V}} 1.4$ immunofluorescence reduced to a similar extent as the apparent active zone size in $C A S T^{-/-}$rods. The occupancy of these sites at a given moment (defining the standing RRP) depends on the ratio of fusion and replenishment (Pangrsic et al., 2010; Jarsky et al., 2011; Oesch and Diamond, 2011). The rate of transmitter release is determined by the product of the standing RRP and the vesicular release probability. Therefore, in the simplest scenario of the $C A S T^{-/-}$disruption at the active zone-in which only the number of release sites is reduced, but $\mathrm{Ca}^{2+}$ influx-exocytosis coupling and replenishment of each release site remain unaltered-release rate should be diminished to the same extent as the active zone size (total RRP). Estimates of maximal rates of sustained transmitter release of salamander retinal photoreceptors in the dark amount to $\sim 200$ vesicles/s per active zone (Rabl et al., 2005; Jackman et al., 2009). The recent study suggests that a reduction of the release rate by $40 \%$ already leads to noticeable visual deficits. Indeed, we found a reduced contrast sensitivity at the level of retinal ganglion cells and the optomotor reflex in $C A S T^{-/-}$mice, which is consistent with proposed role of the vesicle pool dynamics at ribbon synapses for encoding of visual contrast (Jarsky et al., 2011; Oesch and Diamond, 2011). Because our morphological and scotopic ERG analyses focused on rod photoreceptor synapses, we cannot currently exclude that the mutation also affected ribbon synapses of cones and bipolar cells. This work now sets the stage for additional studies of the cellular mechanisms of a reduced number of release sites at the ribbon synapses of $\mathrm{CAST}^{-/-}$mice. For example, it will be interesting to study the $\mathrm{Ca}^{2+}$ current, size of the RRP, and the $\mathrm{Ca}^{2+}$ influxexocytosis coupling at photoreceptor and bipolar cell ribbon synapses of $C A S T^{-/-}$mice. Moreover, high-resolution electron tomography should be used for detailed analysis of synaptic vesicle tethering to the active zone. Together, such experiments will clarify whether specific alterations other than active zone size reduction occur.

\section{References}

Altrock WD, tom Dieck S, Sokolov M, Meyer AC, Sigler A, Brakebusch C, Fässler R, Richter K, Boeckers TM, Potschka H, Brandt C, Löscher W, Grimberg D, Dresbach T, Hempelmann A, Hassan H, Balschun D, Frey JU, Brandstätter JH, Garner CC, et al. (2003) Functional inactivation of a fraction of excitatory synapses in mice deficient for the active zone protein bassoon. Neuron 37:787-800.

Astigarraga S, Hofmeyer K, Farajian R, Treisman JE (2010) Three Drosophila liprins interact to control synapse formation. J Neurosci 30:15358-15368.

Bölinger D, Gollisch T (2012) Closed-loop measurements of iso-response stimuli reveal dynamic nonlinear stimulus integration in the retina. Neuron 73:333-346.

Brandt A, Khimich D, Moser T (2005) Few CaV1. 3 channels regulate the exocytosis of a synaptic vesicle at the hair cell ribbon synapse. J Neurosci 25:11577-11585.

Chang B, Heckenlively JR, Bayley PR, Brecha NC, Davisson MT, Hawes NL, Hirano AA, Hurd RE, Ikeda A, Johnson BA, McCall MA, Morgans CW, Nusinowitz S, Peachey NS, Rice DS, Vessey KA, Gregg RG (2006) The nob2 mouse, a null mutation in Cacnalf: anatomical and functional abnormalities in the outer retina and their consequences on ganglion cell visual responses. Vis Neurosci 23:11-24.

Dai Y, Taru H, Deken SL, Grill B, Ackley B, Nonet ML, Jin Y (2006) SYD-2 Liprin- $\alpha$ organizes presynaptic active zone formation through ELKS. Nat Neurosci 9:1479-1487.

Deguchi-Tawarada M, Inoue E, Takao-Rikitsu E, Inoue M, Kitajima I, Ohtsuka T, Takai Y (2006) Active zone protein CAST is a component of conventional and ribbon synapses in mouse retina. J Comp Neurol 495:480-496.

Dick O, Hack I, Altrock WD, Garner CC, Gundelfinger ED, Brandstätter JH (2001) Localization of the presynaptic cytomatrix protein Piccolo at rib- 
bon and conventional synapses in the rat retina: comparison with Bassoon. J Comp Neurol 439:224-234.

Dick O, tom Dieck S, Altrock WD, Ammermüller J, Weiler R, Garner CC, Gundelfinger ED, Brandstätter JH (2003) The presynaptic active zone protein bassoon is essential for photoreceptor ribbon synapse formation in the retina. Neuron 37:775-786.

Douglas RM, Alam NM, Silver BD, McGill TJ, Tschetter WW, Prusky GT (2005) Independent visual threshold measurements in the two eyes of freely moving rats and mice using a virtual-reality optokinetic system. Vis Neurosci 22:677-684.

Fejtova A, Gundelfinger ED (2006) Molecular organization and assembly of the presynaptic active zone of neurotransmitter release. Results Probl Cell Differ 43:49-68.

Frank T, Rutherford MA, Strenzke N, Neef A, Pangršič T, Khimich D, Fejtova A, Gundelfinger ED, Liberman MC, Harke B, Bryan KE, Lee A, Egner A, Riedel D, Moser T (2010) Bassoon and the synaptic ribbon organize $\mathrm{Ca}^{2+}$ channels and vesicles to add release sites and promote refilling. Neuron 68:724-738.

Goetze B, Schmidt KF, Lehmann K, Altrock WD, Gundelfinger ED, Löwel S (2010) Vision and visual cortical maps in mice with a photoreceptor synaptopathy: reduced but robust visual capabilities in the absence of synaptic ribbons. Neuroimage 49:1622-1631.

Gundelfinger ED, Fejtova A (2012) Molecular organization and plasticity of the cytomatrix at the active zone. Curr Opin Neurobiol $22: 423-430$.

Haeseleer F, Imanishi Y, Maeda T, Possin DE, Maeda A, Lee A, Rieke F, Palczewski K (2004) Essential role of $\mathrm{Ca}^{2+}$-binding protein 4, a Cav1.4 channel regulator, in photoreceptor synaptic function. Nat Neurosci 7:1079-1087.

Hallermann S, Fejtova A, Schmidt H, Weyhersmüller A, Silver RA, Gundelfinger ED, Eilers J (2010) Bassoon speeds vesicle reloading at a central excitatory synapse. Neuron 68:710-723.

Han Y, Kaeser PS, Südhof TC, Schneggenburger R (2011) RIM determines $\mathrm{Ca}^{2+}$ channel density and vesicle docking at the presynaptic active zone. Neuron 69:304-316.

Harlow ML, Ress D, Stoschek A, Marshall RM, McMahan UJ (2001) The architecture of active zone material at the frog's neuromuscular junction. Nature 409:479-484.

Hida Y, Ohtsuka T (2010) CAST and ELKS proteins: structural and functional determinants of the presynaptic active zone. J Biochem 148:131-137.

Hull C, Studholme K, Yazulla S, von Gersdorff H (2006) Diurnal changes in exocytosis and the number of synaptic ribbons at active zones of an ONtype bipolar cell terminal. J Neurophysiol 96:2025-2033.

Jackman SL, Choi SY, Thoreson WB, Rabl K, Bartoletti TM, Kramer RH (2009) Role of the synaptic ribbon in transmitting the cone light response. Nat Neurosci 12:303-310.

Jarsky T, Tian M, Singer JH (2010) Nanodomain control of exocytosis is responsible for the signaling capability of a retinal ribbon synapse. J Neurosci 30:11885-11895.

Jarsky T, Cembrowski M, Logan SM, Kath WL, Riecke H, Demb JB, Singer JH (2011) A synaptic mechanism for retinal adaptation to luminance and contrast. J Neurosci 31:11003-11015.

Kaeser PS, Deng L, Chávez AE, Liu X, Castillo PE, Südhof TC (2009) ELKS2alpha/CAST deletion selectively increases neurotransmitter release at inhibitory synapses. Neuron 64:227-239.

Kaufmann N, DeProto J, Ranjan R, Wan H, Van Vactor D (2002) Drosophila liprin-alpha and the receptor phosphatase Dlar control synapse morphogenesis. Neuron 34:27-38.

Khimich D, Nouvian R, Pujol R, Tom Dieck S, Egner A, Gundelfinger ED, Moser T (2005) Hair cell synaptic ribbons are essential for synchronous auditory signalling. Nature 434:889-894.

Kittel RJ, Wichmann C, Rasse TM, Fouquet W, Schmidt M, Schmid A, Wagh DA, Pawlu C, Kellner RR, Willig KI, Hell SW, Buchner E, Heckmann M, Sigrist SJ (2006) Bruchpilot promotes active zone assembly, $\mathrm{Ca}^{2+}$ channel clustering, and vesicle release. Science 312:1051-1054.

Lazarevic V, Schöne C, Heine M, Gundelfinger ED, Fejtova A (2011) Extensive remodeling of the presynaptic cytomatrix upon homeostatic adaptation to network activity silencing. J Neurosci 31:10189-10200.

Mansergh F, Orton NC, Vessey JP, Lalonde MR, Stell WK, Tremblay F, Barnes S, Rancourt DE, Bech-Hansen NT (2005) Mutation of the calcium channel gene Cacnalf disrupts calcium signaling, synaptic transmission and cellular organization in mouse retina. Hum $\mathrm{Mol}$ Genet 14:3035-3046.

Matthews G, Fuchs P (2010) The diverse roles of ribbon synapses in sensory neurotransmission. Nat Rev Neurosci 11:812-822.

Matz J, Gilyan A, Kolar A, McCarvill T, Krueger SR (2010) Rapid structural alterations of the active zone lead to sustained changes in neurotransmitter release. Proc Natl Acad Sci U S A 107:8836-8841.

Moser T, Neef A, Khimich D (2006) Mechanisms underlying the temporal precision of sound coding at the inner hair cell ribbon synapse. J Physiol 576:55-62.

Mukherjee K, Yang X, Gerber SH, Kwon HB, Ho A, Castillo PE, Liu X, Südhof TC (2010) Piccolo and bassoon maintain synaptic vesicle clustering without directly participating in vesicle exocytosis. Proc Natl Acad Sci U S A 107:6504-6509.

Oesch NW, Diamond JS (2011) Ribbon synapses compute temporal contrast and encode luminance in retinal rod bipolar cells. Nat Neurosci 14:1555-1561.

Ohtsuka T, Takao-Rikitsu E, Inoue E, Inoue M, Takeuchi M, Matsubara K, Deguchi-Tawarada M, Satoh K, Morimoto K, Nakanishi H, Takai Y (2002) Cast: a novel protein of the cytomatrix at the active zone of synapses that forms a ternary complex with RIM1 and munc13-1. J Cell Biol 158:577-590.

Olsen O, Moore KA, Fukata M, Kazuta T, Trinidad JC, Kauer FW, Streuli M, Misawa H, Burlingame AL, Nicoll RA, Bredt DS (2005) Neurotransmitter release regulated by a MALS-liprin-alpha presynaptic complex. J Cell Biol 170:1127-1134.

Pangrsic T, Lasarow L, Reuter K, Takago H, Schwander M, Riedel D, Frank T, Tarantino LM, Bailey JS, Strenzke N, Brose N, Müller U, Reisinger E, Moser T (2010) Hearing requires otoferlin-dependent efficient replenishment of synaptic vesicles in hair cells. Nat Neurosci 13:869-876.

Peichl L (2005) Diversity of mammalian photoreceptor properties: adaptations to habitat and lifestyle? Anat Rec A Discov Mol Cell Evol Biol 287:1001-1012.

Pouzat C, Mazor O, Laurent G (2002) Using noise signature to optimize spike-sorting and to assess neuronal classification quality. J Neurosci Methods 122:43-57.

Prusky GT, Alam NM, Beekman S, Douglas RM (2004) Rapid quantification of adult and developing mouse spatial vision using a virtual optomotor system. Invest Ophthalmol Vis Sci 45:4611-4616.

Rabl K, Cadetti L, Thoreson WB (2005) Kinetics of exocytosis is faster in cones than in rods. J Neurosci 25:4633-4640.

Regus-Leidig H, Tom Dieck S, Specht D, Meyer L, Brandstätter JH (2009) Early steps in the assembly of photoreceptor ribbon synapses in the mouse retina: the involvement of precursor spheres. J Comp Neurol 512:814-824.

Regus-Leidig H, tom Dieck S, Brandstätter JH (2010) Absence of functional active zone protein Bassoon affects assembly and transport of ribbon precursors during early steps of photoreceptor synaptogenesis. Eur J Cell Biol 89:468-475.

Sheets L, Trapani JG, Mo W, Obholzer N, Nicolson T (2011) Ribeye is required for presynaptic CaV1.3a channel localization and afferent innervation of sensory hair cells. Development 138:1309-1319.

Specht D, Tom Dieck S, Ammermüller J, Regus-Leidig H, Gundelfinger ED, Brandstätter JH (2007) Structural and functional remodeling in the retina of a mouse with a photoreceptor synaptopathy: plasticity in the rod and degeneration in the cone system. Eur J Neurosci 26:2506-2515.

Specht D, Wu SB, Turner P, Dearden P, Koentgen F, Wolfrum U, Maw M, Brandstätter JH, tom Dieck S (2009) Effects of presynaptic mutations on a postsynaptic Cacnals calcium channel colocalized with mGluR6 at mouse photoreceptor ribbon synapses. Invest Ophthalmol Vis Sci 50:505-515.

Spiwoks-Becker I, Glas M, Lasarzik I, Vollrath L (2004) Mouse photoreceptor synaptic ribbons lose and regain material in response to illumination changes. Eur J Neurosci 19:1559-1571.

Stigloher C, Zhan H, Zhen M, Richmond J, Bessereau JL (2011) The presynaptic dense projection of the Caenorhabditis elegans cholinergic neuromuscular junction localizes synaptic vesicles at the active zone through SYD-2/liprin and UNC-10/RIM-dependent interactions. J Neurosci 31:4388-4396.

Takao-Rikitsu E, Mochida S, Inoue E, Deguchi-Tawarada M, Inoue M, Oht- 
suka T, Takai Y (2004) Physical and functional interaction of the active zone proteins, CAST, RIM1, and Bassoon, in neurotransmitter release. J Cell Biol 164:301-311.

tom Dieck S, Altrock WD, Kessels MM, Qualmann B, Regus H, Brauner D, Fejtová A, Bracko O, Gundelfinger ED, Brandstätter JH (2005) Molecular dissection of the photoreceptor ribbon synapse: physical interaction of Bassoon and RIBEYE is essential for the assembly of the ribbon complex. J Cell Biol 168:825-836.

Wachman ES, Poage RE, Stiles JR, Farkas DL, Meriney SD (2004) Spatial distribution of calcium entry evoked by single action potentials within the presynaptic active zone. J Neurosci 24:2877-2885.

Zhai RG, Bellen HJ (2004) The architecture of the active zone in the presynaptic nerve terminal. Physiology 19:262-270.
Zhai RG, Vardinon-Friedman H, Cases-Langhoff C, Becker B, Gundelfinger ED, Ziv NE, Garner CC (2001) Assembling the presynaptic active zone: a characterization of an active zone precursor vesicle. Neuron 29:131-143.

Zhai R, Olias G, Chung WJ, Lester RA, tom Dieck S, Langnaese K, Kreutz MR, Kindler S, Gundelfinger ED, Garner CC (2000) Temporal appearance of the presynaptic cytomatrix protein Bassoon during synaptogenesis. Mol Cell Neurosci 15:417-428.

Zhen M, Jin Y (1999) The liprin protein SYD-2 regulates the differentiation of presynaptic termini in C. elegans. Nature 401:371-375.

Zürner M, Mittelstaedt T, tom Dieck S, Becker A, Schoch S (2011) Analyses of the spatiotemporal expression and subcellular localization of liprin- $\alpha$ proteins. J Comp Neurol 519:3019-3039. 